\title{
The prognostic impact of extracapsular lymph node involvement in rectal cancer patients: Implications for staging and adjuvant treatment strategies
}

\author{
J. BRABENDER ${ }^{1}$, E. BOLLSCHWEILER ${ }^{1}$, A.H. HÖLSCHER ${ }^{1}$, K. STROBEL ${ }^{1}$, C. GUTSCHOW ${ }^{1}$, K. PRENZEL $^{1}$, \\ P. GRIMMINGER ${ }^{1}$, U. DREBBER ${ }^{2}$, W. SCHRÖDER ${ }^{1}$, R. METZGER $^{1}$ and D. VALLBÖHMER ${ }^{1}$
}

Departments of ${ }^{1}$ General, Visceral and Cancer Surgery, and ${ }^{2}$ Pathology, University of Cologne, D-50937 Cologne, Germany

Received October 20, 2011; Accepted January 4, 2012

DOI: $10.3892 / \mathrm{ol} .2012 .569$

\begin{abstract}
Limited data suggest that extracapsular lymph node involvement (LNI) has a negative prognostic impact in gastrointestinal malignancies. The aim of this study was to assess the prevalence and prognostic impact of LNI in patients with primary resected rectal cancer. Between 1997 and 2007, 243 rectal cancer patients underwent surgical therapy without neoadjuvant treatment at our Department. Of these, $12(5 \%)$ patients received transanal endoscopic microsurgery and were not included for further analyses. In the remaining patients, a (low) anterior resection was performed in $79 \%$ and an abdominoperineal rectal amputation in $21 \%$. The total number of analyzed lymph nodes and the number of metastatic lymph nodes with/without extracapsular LNI were determined and the prognostic impact of LNI was assessed. The median number of analyzed lymph nodes was 14 . In total, 59\% of patients were node-negative, $18 \%$ of patients were node-positive without extracapsular LNI and 23\% of patients were node-positive with extracapsular LNI. A positive lymph node status with extracapsular LNI was significantly correlated with a poorer $\mathrm{T}-, \mathrm{N}$ - and M-category, grading and more frequent lymphatic vessel infiltration compared with node-negative or node-positive without extracapsular LNI patients $(\mathrm{p}<0.001)$. The overall 5 -year survival rate of node-negative patients was $75 \%$, for node-positive without extracapsular LNI patients $69 \%$ and for node-positive with extracapsular LNI patients $36 \%$ ( $<<0.001$ ). By multivariate analysis, the $\mathrm{N}$-category with extracapsular LNI was characterized as an independent prognostic factor. Extracapsular lymph node involvement reveals an independent negative prognostic impact in patients with rectal cancer undergoing surgical therapy. Staging systems for rectal cancer
\end{abstract}

Correspondence to: Professor Elfriede Bollschweiler, Department of General, Visceral and Cancer Surgery, University of Cologne, Kerpenerstrasse 62, D-50937 Cologne, Germany

E-mail: elfriede.bollschweiler@uk-koeln.de

Key words: rectal cancer, prognostic factors, extracapsular lymph node involvement, adjuvant therapy should include the implementation of extracapsular lymph node involvement.

\section{Introduction}

In rectal cancer, the presence and degree of lymphatic dissemination are the most important factors of prognostic impact $(1,2)$. Moreover, the lymph node status may be refined by the total number of metastatic lymph nodes, the ratio of lymph nodes involved over the total number of analyzed nodes, the absolute number of identified lymph nodes and the presence of lymph node micrometastases in the surgical specimen (3-5).

Although it is well established that the depth of tumor infiltration into the rectal wall, i.e., the pT-status, is of great prognostic value, little attention has been paid to the prognostic impact of the extension of tumor cells through the nodal capsule into the perinodal fatty tissue, i.e. the extracapsular lymph node involvement (LNI). A recent systematic review by Wind et al (1) regarding the evidence on extracapsular LNI as a prognostic factor in gastrointestinal malignancies, revealed only 3 rectal cancer series with a total of 418 lymph node-positive patients, suggesting extracapsular LNI to be a valuable prognostic factor $(1,6-8)$. Moreover, our own working group published 2 studies showing extracapsular LNI to be an independent prognostic factor in esophageal and gastric cancer $(9,10)$.

The potential of tumor cells to invade through the lymph node capsule in an immunologically adversarial environment, most likely reflects the aggressiveness of the primary tumor (11). Therefore, the detection and quantification of extracapsular LNI in the surgical specimen of rectal cancer may be helpful not only for staging, but also for determining adjuvant treatment strategies.

The aim of this study was to assess the prevalence of extracapsular LNI, its correlations with clinicopathological parameters and to determine whether extracapsular LNI is of prognostic impact in rectal cancer.

\section{Patients and methods}

Patient characteristics. Between 1997 and 2007, 243 consecutive rectal cancer patients (151 males, 92 females; median age, 
64 years) underwent primary surgical therapy without any neoadjuvant treatment at our Department. Of these, $12(5 \%)$ patients received transanal endoscopic microsurgery and were not included in further analyses.

A retrospective/prospective analysis of patients' clinicopathological characteristics was performed and formed the basis of this study. This included, in particular, the total number of analyzed lymph nodes, the number of metastatic lymph nodes, and the number of metastatic lymph nodes with/ without extracapsular LNI.

The local Institutional Review Board (IRB) approved this retrospective study and indicated that individual consent could be waived since individual patients were not identified in the study.

Staging. The tumor-node-metastasis (TNM) staging was performed according to the criteria of the International Union Against Cancer using the 6th edition (12). Clinical staging was based on results from endoscopy, endoscopic ultrasound, and computed tomography of the chest and abdomen. Endoscopy and endoscopic ultrasound were performed by a single experienced examiner for all patients.

Surgical resection. A (low) anterior resection was performed in $79 \%$ of the patients, and an abdominoperineal rectal amputation in $21 \%$. The specimens were removed en bloc, including the LNs.

Histopathology. Histopathological examination of all resected specimens consisted of thorough evaluations of tumor stage, residual tumor (R) category, grading, and the number of examined and involved LNs. The specimens were fixed in 5\% formaldehyde and set in paraffin. The LNs were counted and the maximum diameter of each node was measured with a slide gauge. A series of sections from each node were selected and stained with hematoxylin and eosin, as well as with periodic acid-Schiff (PAS). The dissected LNs were microscopically analyzed for metastatic disease. Extracapsular LNI was defined as metastatic cancer extending through the nodal capsule into the perinodal fatty tissue. Examinations of LNs were performed by an experienced pathologist (U.D.). Deposits of metastatic cancer cells without a recognizable lymph node were considered extracapsular LNI, unless these deposits were associated with perineural and/or vessel involvement. In cases of desmoplastic reaction resulting in difficulties in identifying the preexisting lymph node capsule, an imaginary line representing the original capsule was drawn to facilitate interpretation.

Statistical analysis. Data were collected retrospectively according to a standardized protocol. The median, with the minimum and maximum values, was used for descriptive statistics. Chi-square statistics were calculated for frequencies of factors with a significance level of $p<0.05$. Median follow-up time of all patients was calculated using the time between study entry and the date of actual analysis, and the time between study entry and date of censoring for censored patients. Median follow-up time was 5.3 years. Kaplan-Meier plots were used to depict survival distribution. The log-rank test was used to evaluate survival differences. In addition, $95 \%$ confidence intervals $(95 \% \mathrm{CI})$ for the different survival curves were calculated. Postoperative mortality was included in the calculation of prognosis. The multivariate analysis of survival used Cox regression analysis with backward exclusion of variables to identify independent prognostic variables. The level of significance was set at $\mathrm{p}<0.05$. Statistical analyses were performed using the statistical program SPSS version 17.0 for Windows. For graphical presentation of survival curves, the statistical program Medicalc Version 11.4 was used.

\section{Results}

The histopathological data of the 231 study patients are shown in Table I.

Analyzed lymph nodes in the resected specimens. In 231 patients, a total of 3404 lymph nodes (median 14; range $0-54)$ were analyzed. There were 136 (59\%) patients with a negative and $95(41 \%)$ patients with a positive lymph node status. All positive lymph nodes $(n=503)$ were re-examined for the presence of extracapsular LNI. Extracapsular LNI was found in $54(23 \%)$ patients, while in $41(18 \%)$ patients with a positive lymph nodes status no extracapsular LNI was detected.

The median number of resected lymph nodes, the frequency of patients with lymph nodes metastases, as well as the frequency of patients with extracapsular LNI, were not statistically different between patients undergoing (low) anterior resection and abdominoperineal rectal amputation (data not shown).

Correlation of extracapsular lymph node involvement with clinicopathological factors. The presence of extracapsular LNI was significantly correlated with the pT-, N- and M-category, grading and lymphatic vessel infiltration. Patients with the presence of extracapsular LNI had a significantly more frequent advanced tumor infiltration, lymph node involvement, evidence of distant metastases, poorer tumor grading and lymphatic vessel infiltration (Table II A-E).

Correlation of extracapsular lymph node involvement with survival. The 5-year survival rate of patients with a negative lymph node status was $75 \%$, and for patients with a positive lymph node status without extracapsular LNI the 5-year survival rate was $69 \%$. With evidence of extracapsular LNI the 5-year survival rate was reduced to $36 \%(\mathrm{p}<0.001)$, as shown in Fig. 1.

Multivariate analysis of prognosis. Cox-regression analysis including the parameters with a significant influence in the univariate analysis (pT-, N-, M-, R-category, grading and lymphatic vessel infiltration, number of resected lymph nodes and presence of extracapsular lymph node involvement) identified age, gender, metastasis, R0-resection and extracapsular lymph node involvement as independent prognostic factors (Table III).

\section{Discussion}

This study evaluated the prevalence of extracapsular LNI, its correlations with clinicopathological parameters and its 
Table I. Histopathological/demographic data of the 231 study patients and univariate analysis of prognosis.

\begin{tabular}{|c|c|c|c|c|}
\hline Variables & $\begin{array}{l}\text { Number of } \\
\text { patients (n) }\end{array}$ & Frequency $(\%)$ & $\begin{array}{c}\text { 5-year } \\
\text { survival rate }(\%)\end{array}$ & $\begin{array}{c}\text { Significance according to } \\
\text { the 5-year survival rate: } \\
\text { p-value }\end{array}$ \\
\hline All patients & 231 & 100 & 65 & \\
\hline pT-category & & & & $<0.001$ \\
\hline $\mathrm{T} 1$ & 38 & 16 & 79 & \\
\hline $\mathrm{T} 2$ & 58 & 25 & 79 & \\
\hline $\mathrm{T} 3$ & 124 & 54 & 56 & \\
\hline $\mathrm{T} 4$ & 11 & 5 & 36 & \\
\hline pN-category & & & & $<0.001$ \\
\hline N0 & 136 & 59 & 75 & \\
\hline $\mathrm{N} 1 / 2$ & 95 & 41 & 49 & \\
\hline pM-category & & & & $<0.001$ \\
\hline M0 & 182 & 79 & 72 & \\
\hline M1 & 49 & 21 & 25 & \\
\hline R-category & & & & $<0.001$ \\
\hline R0 & 207 & 90 & 72 & \\
\hline $\mathrm{R} 1$ & 7 & 3 & 21 & \\
\hline $\mathrm{R} 2$ & 17 & 7 & 12 & \\
\hline Lymphatic vessel infiltration & & & & $<0.001$ \\
\hline L0 & 165 & 71 & 72 & \\
\hline L1 & 66 & 29 & 47 & \\
\hline Grading & & & & 0.142 \\
\hline $\mathrm{G} 1 / 2$ & 200 & 87 & 67 & \\
\hline G3 & 31 & 13 & 46 & \\
\hline Gender & & & & 0.015 \\
\hline Male & 143 & 62 & 59 & \\
\hline Female & 88 & 38 & 74 & \\
\hline
\end{tabular}

prognostic impact in rectal cancer patients undergoing primary surgical therapy. Our results have shown that a positive lymph node status with extracapsular LNI was significantly correlated with a poorer T-, N-, M- and G-category. Moreover, patients with evidence of extracapsular LNI had a significantly worse 5-year survival rate compared with node-negative or node-positive without extracapsular LNI patients. The presence of extracapsular LNI was characterized as a negative independent prognostic factor.

In a current systematic review on the prognostic impact of extracapsular LNI in gastrointestinal malignancies, Wind et al (1) and other authors identified 3 rectal cancer series with a total of 418 lymph node-positive patients (6-8). The pooled incidence of the 3 studies for extracapsular LNI was $35 \%$, while in our study the prevalence was $57 \%$ in patients with a positive lymph node status. The initial study on the prognostic value of extracapsular LNI in rectal cancer was performed by Ueno et al in 1998 (8). In 217 lymph nodepositive patients, radically resected for rectal cancer, the authors showed that the presence of extracapsular LNI affects the long-term outcome. Similar data were presented by Heide et al and Lupattelli et al in rectal cancer patients undergoing primary surgery $(6,7)$. The two studies described

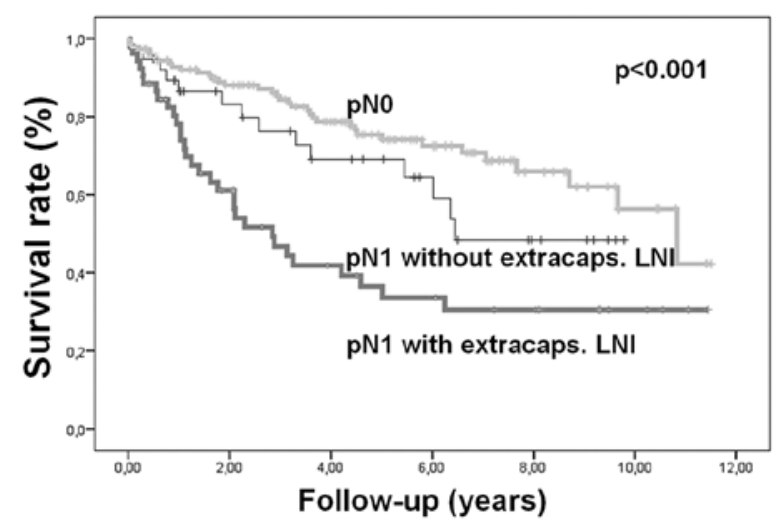

Figure 1. Correlation of extracapsular lymph node involvement with survival.

extracapsular LNI as an independent prognostic factor. Our findings confirm that extracapsular LNI is an independent prognostic factor in rectal cancer.

Similar results were reported in colon cancer as well as in several non-gastrointestinal malignancies, including bladder, breast, cervical, laryngeal and prostate cancer, where 
Table II. Correlation of extracapsular lymph node involvement with clinicopathological factors.

A, pT-category

\begin{tabular}{lccc}
\hline & $\begin{array}{c}\text { Patients with } \\
\text { pN0 status (\%) }\end{array}$ & $\begin{array}{c}\text { Patients with positive } \\
\text { LN-status without LNI (\%) }\end{array}$ & $\begin{array}{c}\text { Patients with positive } \\
\text { LN-status with LNI (\%) }\end{array}$ \\
\hline T1 $(\mathrm{n}=38)$ & 90 & 5 & 5 \\
T2 $(\mathrm{n}=58)$ & 84 & 14 & 2 \\
T3 $(\mathrm{n}=124)$ & 43 & 21 & 36 \\
T4 $(\mathrm{n}=11)$ & 22 & 22 & 56 \\
\hline
\end{tabular}

$\mathrm{B}, \mathrm{pN}$-category

\begin{tabular}{lccc}
\hline & $\begin{array}{c}\text { Patients with } \\
\text { pN0 status (\%) }\end{array}$ & $\begin{array}{c}\text { Patients with positive } \\
\text { LN-status without LNI (\%) }\end{array}$ & $\begin{array}{c}\text { Patients with positive } \\
\text { LN-status with LNI (\%) }\end{array}$ \\
\hline N1 $(n=43)$ & - & 60 & 40 \\
N2 $(n=52)$ & - & 25 & 74 \\
\hline
\end{tabular}

C, pM-category

\begin{tabular}{cccc}
$\begin{array}{c}\text { Patients with } \\
\text { pN0 status }(\%)\end{array}$ & $\begin{array}{c}\text { Patients with positive } \\
\text { LN-status without LNI (\%) }\end{array}$ & $\begin{array}{c}\text { Patients with positive } \\
\text { LN-status with LNI (\%) }\end{array}$ & p-value \\
\hline 76 & 16 & 15 & $<0.001$ \\
15 & 22 & 63 &
\end{tabular}

D, Grading

\begin{tabular}{cccc}
$\begin{array}{c}\text { Patients with } \\
\text { pN0 status }(\%)\end{array}$ & $\begin{array}{c}\text { Patients with positive } \\
\text { LN-status without LNI }(\%)\end{array}$ & $\begin{array}{c}\text { Patients with positive } \\
\text { LN-status with LNI (\%) }\end{array}$ & p-value \\
\hline 66 & 16 & 18 & $<0.001$ \\
27 & 23 & 50 & \\
\hline
\end{tabular}

E, Lymphatic vessel infiltration

\begin{tabular}{lccc}
\hline & $\begin{array}{c}\text { Patients with } \\
\text { pN0 status (\%) }\end{array}$ & $\begin{array}{c}\text { Patients with positive } \\
\text { LN-status without LNI (\%) }\end{array}$ & $\begin{array}{c}\text { Patients with positive } \\
\text { LN-status with LNI (\%) }\end{array}$ \\
\hline L0 $(\mathrm{n}=165)$ & 73 & 14 & 13 \\
L1 $(\mathrm{n}=66)$ & 29 & 23 & 48
\end{tabular}

LN-status, lymph node status; LNI, lymph node involvement.

a significant prognostic value of extracapsular lymph node involvement has already been described (13-18). The study findings are also in agreement with the two studies our working group published on the prognostic impact of extracapsular LNI in esophageal and gastric cancer $(9,10)$. In the first study, 243 patients with resected esophageal cancer without neoadjuvant therapy were studied (9). A total of 738 lymph node metastases were examined and the prevalence and prognostic impact of extracapsular LNI was assessed. Our results demonstrated that extracapsular LNI was an independent negative prognostic factor, while it was observed significantly more often in esophageal adenocarcinoma than in squamous cell carcinoma (9). In their study, Alakus et al analyzed the prognostic value of extracapsular LNI in 159 gastric cancer patients who underwent (subtotal) gastrectomy with D2-lymphadenectomy (10). Extracapsular LNI was present in $35.8 \%$ of the patients and was significantly associated with higher pN-category, pM category and higher UICC stages. Moreover, extracapsular LNI was significantly associated with poor survival independent to other prognostic factors.

The prognostic impact of extracapsular LNI may have significant implications for staging and adjuvant treatment 
Table III. Multivariate analysis of prognosis.

\begin{tabular}{|c|c|c|c|c|}
\hline Variables & $\mathrm{n}=231$ & Hazard ratio & $95 \% \mathrm{CI}$ & p-value \\
\hline Gender & & & & 0.003 \\
\hline Male & 143 & 1 & & \\
\hline Male - female & 88 & 0.43 & $0.2-0.7$ & \\
\hline pN category with extracapsular LNI & & & & 0.021 \\
\hline pNO & 136 & 1 & & \\
\hline pN0-pN1- & 43 & 1.07 & $0.5-2.2$ & \\
\hline pN0-pN1+ & 52 & 2.12 & $1.2-4.7$ & \\
\hline pM category & & & $\mathrm{p}=0.008$ & \\
\hline pM0 & 182 & 1 & & \\
\hline pM0-pM1 & 49 & 2.63 & $1.3-5.4$ & \\
\hline R category & & & & 0.045 \\
\hline R0 & 207 & 1 & & \\
\hline R0-R1/R2 & 24 & 2.26 & $1.02-5.02$ & \\
\hline Age (each year) & & 1.05 & $1.03-1.08$ & $<0.001$ \\
\hline
\end{tabular}

LNI, lymph node involvement; CI, confidence interval.

strategies in rectal cancer. It may affect the UICC staging system, which currently only considers the number of metastatic lymph nodes but not the characteristics of the metastatic lymph node itself (2). An additional evaluation of extracapsular LNI may add prognostic value to the UICC system. By contrast, quantification of extracapsular LNI in the surgical resection specimen of rectal cancer may be useful to individualize adjuvant treatment strategies in rectal cancer. Patients with evidence of extracapsular LNI are likely to benefit from additional therapeutic drugs, including biological drugs. Moreover, the use of this pathological finding for a tailored approach in the neoadjuvant setting requires a diagnostic tool that would be able to discriminate preoperatively between positive nodes with and without extracapsular LNI.

At this point, we may only speculate as to the reasons for the worse prognosis correlated with extracapsular LNI. Among the possible reasons are: a) extracapsular LNI reveals the aggressivity of the primary tumor, even in an immunologically adverse setting; b) extracapsular LNI is capable of initiating an obstruction of lymphatic vessels, which may lead to an abnormal flow of lymph fluid, possibly inducing communication between lymphatic and venous vessels; c) tumor dissemination across the node capsule may result in microscopic residual tumor cells following node dissection, leading to an increased local failure rate.

An important point of criticism consists of the varying definition of extracapsular LNI. In our study, extracapsular LNI was defined as the infiltration of tumor cells across the lymph node capsule. Notably, Wind et al revealed in their systematic review that there is no uniform definition of this pathological finding (1). Certain studies included micro dissemination in adjacent tissues, while other studies included deposits without a recognizable lymph node or involvement of afferent lymphatic vessels adjacent to the lymph node (1). Moreover, extracapsular LNI is frequently linked with a desmoplastic reaction. This association may lead to a great difficulty in the detection of extracapsular LNI, which may result in a high inter-observer variability.

Another critical point of this study is the fact that we did not evaluate the presence of perineural invasion in our study patients, which is thought to be an additional prognostic factor in this type of cancer (19). Therefore, whether a positive extracapsular LNI status remains an independent prognostic factor in the presence of perineural invasion assessment remains to be determined. However, to the best of our knowledge, no studies have analyzed the correlation between extracapsular LNI and perineural invasion in rectal cancer patients, and this should be performed in future analyses.

In conclusion, our study has shown that extracapsular LNI has an independent prognostic impact in rectal cancer patients undergoing primary surgical therapy. This important prognostic finding may have implications for staging and adjuvant treatment strategies in rectal cancer. Our data are hypothesis generating, therefore prospective studies are warranted.

\section{References}

1. Wind J, Lagarde SM, Ten Kate FJ, et al: A systematic review on the significance of extracapsular lymph node involvement in gastrointestinal malignancies. Eur J Surg Oncol 3: 401-408, 2007.

2. Edge SB, Byrd DR, Carducci MA, et al: American Joint Committee on Cancer (AJCC): Cancer staging manual. 7th edition. Springer, New York, 2009.

3. Doekhie FS, Kuppen PJ, Peeters KC, et al: Prognostic relevance of occult tumour cells in lymph nodes in colorectal cancer. Eur J Surg Oncol 32: 253-258, 2006.

4. Kim YW, Kim NK, Min BS, et al: The influence of the number of retrieved lymph nodes on staging and survival in patients with stage II and III rectal cancer undergoing tumor-specific mesorectal excision. Ann Surg 249: 965-972, 2009.

5. Ng M, Roy-Chowdhury S, Lum SS, et al: The impact of the ratio of positive to total lymph nodes examined and outcome in colorectal cancer. Am Surg 75: 873-876, 2009. 
6. Heide J, Krull A and Berger J: Extracapsular spread of nodal metastasis as a prognostic factor in rectal cancer. Int $\mathbf{J}$ Radiat Oncol Biol Phys 58: 773-778, 2004.

7. Lupattelli M, Maranzano E, Bellavita R, et al: Adjuvant radiochemotherapy in high-risk rectal cancer results of a prospective non-randomized study. Tumori 87: 239-247, 2001.

8. Ueno H, Mochizuki H and Tamakuma S: Prognostic significance of extranodal microscopic foci discontinuous with primary lesion in rectal cancer. Dis Colon Rectum 41: 55-61, 1998.

9. Metzger R, Drebber U, Baldus SE, et al: Extracapsular lymph node involvement differs between squamous cell and adenocarcinoma of the esophagus. Ann Surg Oncol 16: 447-453, 2009.

10. Alakus H, Hölscher AH, Grass G, et al: Extracapsular lymph node spread: a new prognostic factor in gastric cancer. Cancer 16: $309-315,2010$

11. Stitzenberg KB, Meyer AA, Stern SL, et al: Extracapsular extension of the sentinel lymph node metastasis: a predictor of non-sentinel node tumor burden. Ann Surg 237: 607-612, 2003

12. UICC: TNM Classification Of Malignant Tumours. Sobin LH and Wittekind C (eds). 6th edition. Wiley-Liss, New York, 2002

13. Wind J, Ten Kate FJ, Kiewiet JJ, et al: The prognostic significance of extracapsular lymph node involvement in node positive patients with colonic cancer. Eur J Surg Oncol 34: 390-396, 2008.
14. Fleischmann A, Thalmann GN, Markwalder R and Studer UE: Prognostic implications of extracapsular extension of pelvic lymph node metastases in urothelial carcinoma of the bladder. Am J Surg Pathol 29: 89-95, 2005.

15. Ilknur GB, Hilmi A, Tülay C, et al: The importance of extracapsular extension of axillary lymph node metastases in breast cancer. Tumori 90: 107-111, 2004.

16. Metindir J and Bilir Dilek G: Evaluation of prognostic significance in extracapsular spread of pelvic lymph node metastasis in patients with cervical cancer. Eur J Gynaecol Oncol 29: 476-478, 2008.

17. Brasilino de Carvalho M: Quantitative analysis of the extent of extracapsular invasion and its prognostic significance: a prospective study of 170 cases of carcinoma of the larynx and hypopharynx. Head Neck 20: 16-21, 1998.

18. Griebling TL, Ozkutlu D, See WA and Cohen MB: Prognostic implications of extracapsular extension of lymph node metastases in prostate cancer. Mod Pathol 10: 804-809, 1997.

19. Peng J, Sheng W, Huang D, et al: Perineural invasion in pT3N0 rectal cancer: the incidence and its prognostic effect. Cancer 117: 1415-1421, 2011. 